\title{
HAVIA ALGUMA CIÊNCIA NO BRASIL SETECENTISTA?
}

Carlos A. L. Filgueiras*

Departamento de Química - ICEx-UFMG - 31.270-901 - Belo Horizonte - MG

Recebido em 28/4/97; aceito em 3/10/97

\begin{abstract}
WAS THERE ANY SCIENCE IN EIGHTEENTH-CENTURY BRAZIL? In the past decade several articles have been published in this journal and elsewhere by different authors, dealing with the institutionalization of science in Brazil, its origins and subsequent history. The emphasis has often been directed to the work of Brazilian scientists working abroad, to foreigners in Brazil, or to a few private individuals within the country, as well as to cultural, social, economic and political considerations. Much of the attention has also been focused on "academic" science, rather than on empirical or technical developments. The present article presents some of these situations, particularly in the mining district, where the application of technology, sometimes quite up-to-date for the time, tended to blur somewhat the distinction between science and its applications. It is hoped that this may start a debate which will enrich our historiography in this field and be of interest to those who want to assess Brazil's position in the history of science.
\end{abstract}

Keywords: science in Brazil; colonial science; science, technology and society.

Durante o século dezoito, a Revolução Científica iniciada no Renascimento alastrou-se gradualmente por toda a Europa e mesmo fora dela, em países como o México e os Estados Unidos. O século vivenciou também a chamada Revolução Química, cujas realizações empolgaram vários brasileiros que estudaram na Europa, seja em Portugal ou em outros países, como tem sido freqüentemente relatado nas páginas de Química Nova por vários autores. A ciência tinha propagandistas em todos os estratos sociais, e era vista como a grande alavanca do progresso, do desenvolvimento e da prosperidade, vislumbrados como conseqüência quase inevitável de seu cultivo e aplicação generalizados.

Por tudo isso é conveniente indagar se se pode falar na existência de ciência no Brasil do século dezoito. Sem dúvida, a ciência como busca desinteressada de conhecimento da natureza, praticada de forma contínua ou regular, com o patrocínio do estado ou de mecenas particulares, era inexistente. No entanto, havia conhecimento e prática de técnicas, às vezes bem precisas, como exigiam a mineração e a metalurgia, por exemplo. Muitas dessas técnicas, como as análises do teor de metal precioso nos minérios, das medições geodésicas para a delimitação de fronteiras e cartografia, pressupunham algum conhecimento teórico. $\mathrm{Na}$ segunda metade do século, fundaram-se no Rio de Janeiro, sob a égide de Vice-Reis sucessivos, o Marquês do Lavradio e D. Luís de Vasconcelos, duas associações que tinham por finalidade o cultivo e a disseminação das ciências, emulando as academias que proliferavam na Europa. Foram elas, respectivamente, a Academia Científica, de 1772, e a Sociedade Literária do Rio de Janeiro, de 1786. Infelizmente as duas associações tiveram existência fugaz e não alcançaram o papel que pretendiam de propulsoras do desenvolvimento científico. A evidência remanescente hoje do que foi tratado nas reuniões e publicado pelos membros dessas sociedades, embora seja material exíguo, permite dizer que ao menos algumas pessoas na colônia tinham conhecimento e estudavam mesmo algo da ciência que se fazia na Europa. Na ausência de instituições formais para o cultivo das ciências, vários particulares as estudavam de forma autodidática. O estudo das bibliotecas da época, da forma de disseminação de informação, da circulação de livros, muitos

Endereço atual: Departamento de Química Inorgânica - IQ - UFRJ - CP 68563 - 21945-970 - Rio de Janeiro - RJ deles proibidos, e dos contactos entre aquelas pessoas constituem um capítulo ainda escassamente estudado da história das idéias na sociedade de então. A situação tende, porém, a inverter-se, sendo este um tema de estudos recentes de bastante interesse ${ }^{1}$.

Deixando de lado a ciência acadêmica ou formal, e passando para a área de suas aplicações técnicas, pode-se dizer que a situação muda consideravelmente. Basta pensar na importância que tinha o conhecimento técnico na principal atividade econômica colonial da época, a mineração e a metalurgia. Por tudo isso, julgo importante que nos debrucemos sobre esta questão, construindo a partir das fontes e depoimentos existentes um mosaico, ainda que incompleto e mesmo rudimentar, do panorama que é possível pintar daquele Brasil. Reflexões dessa natureza podem ser muito úteis nas avaliações dos rumos de nossa ciência atual, e dos caminhos e descaminhos que ela trilha. Ainda há muito o que fazer para levantar fontes documentais inéditas que jazem em arquivos no Brasil e no estrangeiro, mas acredito que a amostragem aqui apresentada poderá servir como ponto de partida para um debate sobre esse assunto. Embora o trabalho apresentado aqui tenha mais dados a respeito da Capitania de Minas Gerais, isto não é descabido para a época, por ser ela a região mais populosa do Brasil de então e por concentrar as atenções da metrópole, em virtude dos lucros que lhe proporcionava.

Em 21 de março de 1769, uma Carta Régia de D. José I ao Governador de Minas Gerais dizia : "Faço saber a vós Governador e Capitão General da Capitania das Minas Gerais, que por parte de Manoel Alves Correa, assistente do Arraial de N.S. da Piedade da Parabipeva, filial do Curral del Rei (a atual Belo Horizonte), se me fez a petição cuja cópia se vos remete inclusa e na qual pede lhe faça mercê conceder-lhe licença para abrir a dita fábrica de ferro, porque dela resulta benefício ao bem comum, e poder-se aumentar os reais quintos. Me pareceu ordenar-vos informeis com o vosso parecer".?

O texto desta carta é interessante ao mostrar a aparente disposição do governo metropolitano, encabeçado pelo Marquês de Pombal, em atender a uma iniciativa de desenvolvimento manufatureiro no Brasil, qual seria a instalação da fábrica de ferro do tal Manoel Alves Correa. Essa disposição seria posta pelo avesso no reinado seguinte, com a repressão que se instauraria a partir de 1777, quando a morte inesperada de D. José levaria à viradeira política que se instalou com a ascensão de D. Maria I. 
Os pareceres submetidos ao Governador Gomes Freire de Andrade, Conde de Bobadela, deixam bem claro que a produção de ferro e ferramentas do metal eram essenciais para continuar a exploração de ouro, que já escasseava. O ouvidor da Comarca de Sabará, José Francisco Lobo Pessanha, embora favorável, mostra o que hoje chamaríamos de preocupação ecológica : "ocorre-me porém o inconveniente do consumo das madeiras ... que há de ser grande para poder subsistir a fábrica de ferro, visto não haver carvão de pedra, e por isso ... se deve designar sítio para o fazer no qual nãoseja prejudicial o consumo das madeiras e lenhas que tirar para a mesma fábrica."3 Por outro lado, João Caetano Soares Barreto, de Vila Rica, observa ao Governador que "a extração do ouro está presentemente mais dificultosa por se terem ocupado os ditos Mineiros nas lavras e rios mais fáceis, que já lhe não fazem conta, e só lhes restam os morros e cachoeiras em que é mais difícil a extração e em que se gasta muito ferro. Por este princípio se experimenta cada ano maior falta no Quinto, e estão os moradores desta capitania pobres como a V. Exa. é notório."4

Toda essa tramitação burocrática aparentemente favorável acabou não resultando em nada, apesar dos ensaios em pequena escala já feitos por Manoel Alves Correa, com o incentivo do Governador. Não obstante, a iniciativa é digna de nota, tendo ocorrido cerca de meio século antes do início da produção de ferro no país. Vê-se também que já havia algum conhecimento técnico na capitania e uma consciência em certos círculos de que a implantação de manufaturas era essencial para manter e fazer progredir a sociedade.

Como se pode aquilatar o tipo de conhecimento técnico existente no Brasil colonial? A resposta a esta pergunta é difícil e deve ser buscada em geral de forma indireta. Ignorando o brilho efêmero dos trabalhos científicos dos holandeses no nordeste do Brasil $^{5}$, que não produziram consequiências no país, um dos aspectos mais importantes é a investigação do ensino que se praticava na colônia.

Embora a administração colonial portuguesa não tivesse a educação ou a cultura como prioridades, os jesuítas estabeleceram uma verdadeira rede de instituições de ensino ao longo da costa brasileira. Vários colégios jesuítas funcionavam como universidades de fato, à semelhança da Universidade de Évora, e concediam graus de licenciado e mestre ${ }^{6}$. Os diplomas não tinham, porém, validade legal, pois as instituições brasileiras jamais tiveram permissão para se constituir em universidades de direito, pela oposição da Universidade de Coimbra, a quem competia opinar a respeito das seguidas petições dos jesuítas ao governo ${ }^{7}$. Apesar das dificuldades, o êxito dos padres foi notável em suas várias instituições, em Salvador, no Rio de Janeiro ou em Olinda, para citar as mais conhecidas. É de lastimar a perda dos arquivos dessas escolas por ocasião da expulsão pombalina, pois os róis de livros que chegaram até nós, embora fragmentários, mostram acervos bastante interessantes em termos de obras proscritas no Reino, e de importância científica ou filosófica. Só o Colégio do Rio de Janeiro possuía 84 tomos do "Cursus Philosophicus", de Francisco Soares Lusitano, de 1651, em que não só se considerava Aristóteles inadequado, como se esposava a teoria recente da circulação sangüínea de Harvey, proibida de ser ensinada no reino ${ }^{6}$. Uma possível indicação de que algum ensino científico seria ministrado pode ser vislumbrada nos vários projetos de bombas mecânicas para água elaborados e "patenteados" por Bartolomeu Lourenço de Gusmão quando de sua estada no Seminário da Cachoeira, próximo a Salvador, e do projeto dos pequenos balões de ar quente que levou para Portugal e pôs em prática no mesmo ano, $1709^{8}$.

O ensino da engenharia militar iniciou-se em 1699 no Rio de Janeiro, com a fundação da "Aula de Fortificação". Com os nomes sucessivos de "Aula do Terço", "Regimento de Fortificação" e "Real Academia de Artilharia, Fortificação e Desenho" o estabelecimento seguiu seu curso até ser transformado em 1810 na "Academia Real Militar", antecessora direta da atual Escola de Engenharia da UFRJ ${ }^{5}$. No século 18 pontificou como professor a figura notável do matemático e engenheiro José Fernandes Pinto Alpoim, autor de livros e de importantes edificações ao longo de todo o país, muitas delas ainda em uso. Um desses edifícios é o palácio dos governadores de Vila Rica, projetado e fiscalizado por ele e executado por Manuel Francisco Lisboa, pai do Aleijadinho, e terminado de fazer em $1748^{9}$.

As Minas Gerais não foram atingidas diretamente pela ruptura no sistema educacional causada pela expulsão dos inacianos em 1759 , já que as ordens religiosas haviam sido proibidas de se instalar na capitania. O mais importante centro de estudos de Minas era o Seminário de N. S. da Boa Morte, em Mariana. Provavelmente aí se ensinariam alguns tópicos científicos. O futuro químico e professor de Coimbra Vicente Coelho de Seabra Silva Telles aí estudou em $1781^{10}$. Seu conterrâneo de Congonhas do Campo, Cônego Luís Veira da Silva, era professor de filosofia no Seminário e proprietário de uma das mais importantes bibliotecas privadas do Brasil colonial, contando em suas centenas de volumes com várias obras científicas. $\mathrm{O}$ rol desses livros consta dos Autos da Devassa da Inconfidência Mineira, de que o cônego seria protagonista e, como tal, teria os bens confiscados quando de sua prisão ${ }^{11}$.

$\mathrm{O}$ estudo do conhecimento técnico empírico que se utilizava na época é difícil pela diversidade das fontes e sua freqüente precariedade.

Vários códices setecentistas ostentam listas de materiais de instituições que dispunham de meios e, presumivelmente, de pessoal para realizar operações técnicas as mais variadas. Assim a Intendência da Comarca do Rio das Velhas, de Sabará, lista minuciosamente um longo rol de instrumentos e materiais adquiridos entre 1763 e 1766, que evidencia a execução de ensaios químicos e trabalhos metalúrgicos diversos; entre os inúmeros itens contam-se quatro balanças de diferentes capacidades ou sensibilidades, fornos e seus acessórios, almofariz de bronze, mais de dois mil cadinhos, várias arrobas de reagentes importantes como o solimão (sublimado corrosivo, ou cloreto mercúrico) e a água forte (ácido nítrico) ${ }^{12}$.

Uma relação também interessante se pode ver nas compras feitas no Rio de Janeiro pela Câmara de Vila Rica para servir às fortificações daquela praça em 1767. Neste caso, entre os materiais adquiridos estavam grandes quantidades de salitre refinado e enxofre, evidenciando a preparação local de pólvora (que também era importada pronta). Também haviam sido comprados na ocasião quantidades consideráveis de pigmentos e materiais usados em pintura, mas que necessitavam de manipulação profissional para serem usados. Entre esses materiais contavam-se o cinábrio (sulfeto de mercúrio, usado como pigmento vermelho), o pez negro, o antimônio, o mercúrio sublimado, a cola armênia, a caparrosa (sulfato ferroso, usado, entre outras coisas, na fabricação do pigmento azul mais importante e disseminado na época, o azul da Prússia), o sal amoníaco, o verdete (acetato de cobre, importante pigmento verde), a pedra-ume (alume de potássio, usado em tinturaria, no fabrico de laca, de tinta preta, e em curtumes), a terebentina, o breu e a cera amarela. Há ainda registro de pagamento a um certo Sebastião Brandão pela destilação de água forte, atividade altamente temerária de executar ${ }^{13}$.

Foi nesse ambiente que surgiram várias vocações de futuros cientistas, como José Álvares Maciel, Vicente Coelho de Seabra Silva Telles, Manoel Ferreira da Câmara Bittencourt e Sá, e João Manso Pereira. Este último, por jamais ter saído do Brasil, não dispondo, como seus contemporâneos, de uma educação universitária européia, mostraria um reflexo mais fidedigno do aprendizado técnico disponível na colônia. Por isso seus livros e sua obra são tão interessantes em mostrar o quê e como seria possível a alguém instruir-se naqueles assuntos ${ }^{14}$.

Também na área de saúde havia grandes deficiências; a inexistência de escolas de medicina no Brasil e a conseqüente escassez de médicos estimulava a proliferação das práticas populares e das obras de divulgação médica. A arte de boticário era aprendida com mestres aprovados e os aprendizes examinados por médicos para receber a licença de assentar botica ${ }^{15}$.

Entre as obras médicas de uso generalizado no século 18 , 
duas tiveram grande voga no Brasil. A primeira, publicada em Lisboa em 1735, de autoria de Luís Gomes Ferreira, foi o "Erário Mineral"16, constando de doze tratados. A obra, considerada por especialista moderno um "repositório de impropriedades médicas"17, é de grande alento e estende-se em longas minúcias. Como ilustração, o Tratado $\mathrm{V}$ tem um sabor já arcaico de iatroquímica, e se intitula "Da rara virtude do óleo de ouro e das muitas enfermidades para que serve, e observações de curas excelentíssimas, que com ele se tem feito". Apesar de apresentar fartas descrições de casos médicos, tanto no Reino como no Brasil, em que usara o óleo de ouro, o autor se escusa em descrever seu preparo: "óleo de ouro se faz com sal, água forte e ouro, cuja receita anda em vários autores, e por essa causa a não exponho." Evidentemente, o processo químico de dissolução do ouro pela água régia está correto, em linhas gerais, de nosso ponto de vista moderno.

O "Erário" é o produto de uma larga experiência de várias décadas do autor no Brasil, em especial em Minas Gerais, e é um documento precioso ao mostrar com minúcias o tipo de medicina ministrada então. Todavia, alguns dos tratamentos preconizados chegam a constituir-se em torturas bárbaras, de eficácia duvidosa ou nula.

Também esteve no Brasil, em particular em Minas Gerais no início do século (1705-1714) o médico José Rodrigues de Abreu, discípulo do médico e químico alemão Georg Stahl, tão conhecido por sua teoria do flogisto. Rodrigues de Abreu foi o introdutor na medicina portuguesa da teoria do vitalismo, proposta por Stahl e presente na medicina e na Química até sua conhecida refutação por Wöhler no século dezenove. Rodrigues de Abreu expõe suas idéias em sua alentada obra em três volumes denominada "Historiologia Médica", publicada entre 1733 e $1745^{18}$.

O outro livro médico de grande nota no Brasil século 18 , além do "Erário Mineral", deveu-se a José Antônio Mendes, delegado do Cirurgião-Mor do Reino em Minas Gerais. Após viver por mais de trinta anos praticando a medicina no Serro Frio, publicou em 1770 o "Governo dos Mineiros, mui necessário para os que vivem distantes de professores seis, oito, dez, e mais léguas". ${ }^{19}$ Este foi um livro escrito com a intenção específica de ser um manual médico para o uso de leigos ${ }^{17}$.

A participação em academias envolveu vários brasileiros desde cedo. Em 1749 funda-se no Porto a Real Academia Médico-Portopolitana, cujos estatutos, publicados no mesmo ano, registram um "círculo brasiliense" de sete "acadêmicos experimentais", sendo um no Rio de Janeiro e os outros distribuídos por Vila Rica e Mariana ${ }^{20}$.

A necessidade de formar médicos no Brasil era tão grande que em 1808 o Príncipe Regente criou dois colégios médico-cirúrgicos : o primeiro, em Salvador, durante a escala que fez em sua viagem de vinda de Portugal; o segundo, pouco mais tarde, no Rio de Janeiro. Todavia, já se havia fundado bem antes, em 1801, no antigo Hospital de Vila Rica, uma instituição desse gênero; em Carta Régia ao Governador Bernardo José de Lorena, de 17 de junho de 1801, o Príncipe dizia: "sou servido estabelecer no Hospital de Vila Rica uma Cadeira de Cirurgia, Anatomia e Arte Obstetrícia, nomeando para ela o atual Cirurgião-mor do Regimento de Cavalaria de Minas Gerais, Antônio Vieira de Carvalho"21. Além deste, a Cadeira foi também exercida por seu sucessor, Antônio José Vieira de Menezes, até sua morte em 1848, quando cessam as atividades de ensino médico em Ouro Preto ${ }^{21}$.

As três últimas décadas do século dezoito presenciaram a fundação e a vida efêmera das duas sociedades mencionadas anteriormente, destinadas ao cultivo das ciências na capital da colônia: a Academia Científica e a Sociedade Literária do Rio de Janeiro. Nos relatos sobreviventes de suas atividades pode-se entrever um pouco das idéias e convicções daqueles que pretendiam cultivar a ciência de forma menos empírica, tentando passar do mero tecnicismo a algo mais bem fundamentado ${ }^{14,22}$. Essas tentativas, no entanto, eram ainda prematuras, e seria necessário esperar alguns anos para ver a fundação das primeiras instituições científicas de fato no país. Embora muitas vezes precárias, elas começaram a surgir a partir de 1808 , numa tentativa de aplicação tardia dos princípios iluministas do século anterior.

\section{REFERÊNCIAS}

1. Villalta, L. C., "Livrarias e leitura nas Minas Gerais da Época da Inconfidência", Dissertação de Mestrado, Universidade de São Paulo, 1995.

2. Códice SC 166, p. 58, Arquivo Público Mineiro (APM).

3. Ibid., p. 61

4. Ibid., p. 63.

5. Filgueiras, C. A. L., "Origens da Ciência no Brasil", Quím. Nova 1990, 13, 222.

6. Leite, S., "O Curso de Filosofia e Tentativas para se Criar a Universidade do Brasil no Século XVII", Verbum 1948, 5, 107.

7. Castelo-Branco, F., "Tentativa de Criação de uma Universidade no Brasil, no Século XVII", Anais da Academia Portuguesa de História, 2- série 1972, 21, 621.

8. Filgueiras, C. A. L., "Bartolomeu de Gusmão - um Eco da Revolução Científica no Brasil Colonial", em AlfonsoGoldfarb, A. M., e Maia, C. A., orgs., "História da Ciência: o mapa do conhecimento", Expressão e Cultura Edusp, 1995, pp. 381-390.

9. Alpoim, J. F. P., "Exame de Artilheiros", reprodução fac-similar da obra de 1744, nota biográfica e análise crítica de P. Pardal, Biblioteca Reprográfica Xerox, Rio de Janeiro, 1987.

10. Livro de Contas do Seminário de Mariana, 1780-1802, Arquivo Eclesiástico da Arquidiocese de Mariana (AEAM).

11. Autos de Devassa da Inconfidência Mineira, Imprensa Oficial de Minas Gerais, Belo Horizonte, vol. 6, 1982.

12. Receita e Despeza dos Materiaes da Intendencia da Comarca do Rio das Velhas, Códice DF 1160, APM.

13. Almoxarifado da Câmara de Villa Rica - 1767-68, Códice DF 1172, APM

14. Filgueiras, C. A. L., "João Manso Pereira e a Química Empírica no Brasil Colonial”, Quím. Nova 1993, 16, 155.

15. Livro de Registros de Cartas de Provisões, Patentes e Sesmarias: 1755-1772, I - 2.1 557, Arquivo Municipal de Mariana (AMM).

16. Ferreira, L. G., "Erário Mineral, dividido em doze tratados, dedicado, e oferecido à puríssima e sereníssima Virgem Nossa Senhora daConceição. Autor Luís Gomes Ferreira, Cirurgião aprovado, natural da Vila de S. Pedro de Rates, e assistente nas Minas do ouro por discurso de vinte anos". Lisboa Ocidental. Na Oficina de Miguel Rodrigues, Impressor do Senhor Patriarca. 1735.

17. Santos Filho, L., "História Geral da Medicina Brasileira", vol. 1, Hucitec-Edusp, São Paulo, 1977.

18. Rodrigues de Abreu, J., "Historiologia Médica, Fundada e Estabelecida nos Princípios de George Ernesto Stahl, famigeradíssimo Escritor do presente Século, e ajustado ao Uso Practico deste Paiz", tomos I-III, Lisboa, 173345.

19. Mendes, J. A., "Governo de Mineiros mui necessário para os que vivem distantes de professores seis, oito, dez e mais léguas, padecendo por esta causa os seus domésticos e escravos queixas, que pela dilação dos remédios se fazem incuráveis, e as mais das vezes mortais", Lisboa, na Oficina de Antônio Rodrigues Galhardo, 1770.

20. Estatutos da Real Academia Médico-Portopolitana, Porto, 1749.

21. Pieruccetti, F., "Em Minas, O Início do Ensino Médico no Brasil", Rev. Méd. Minas Gerais 1992, 2, 191.

22. Filgueiras, C. A. L., "The Mishaps of Peripheral Science; the Life and Work of Manoel Joaquim Henriques de Paiva, Luso-Brazilian Chemist and Physician of the Late Eighteenth Century", Ambix 1992, 39, 75. 